\section{The Use of Passive Leg Raise Test to Predict Hypotension in Patients Undergoing Urolog- ical Procedures under Spinal Anesthesia}

\section{Mai Wedad Abdullah, Mona Hossam EL Din Abdelhamid*, Nor- han Abdel Aleim Ali and Atef Galal Abdel Moula}

Department of Anesthesia and Pain Management, Faculty of Medicine Cairo University, Egypt

\begin{abstract}
Aim of study: A prospective observational study to examine whether Passive Leg Raise Test (PLR) administered with non invasive cardiac output monitoring by the electrical Cardiometry could be used before spinal anesthesia to determine which patients are at greatest risk for developing spinal hypotension during urological surgery.

Patients and methods: Written informed consent was taken from fourty patients, undergoing urological procedures under spinal anesthesia and were divided into two groups based on their hemodynamic response to the PLR test, routine preparations for operation under spinal anesthesia were made, cardiac output was measured non invasively using Electrical Cardiometry systemic arterial pressure was recorded at 3 minutes intervals at the onset of the block, 5 minutes intervals for the following 30 minutes, then 15 minutes intervals until the resolution of the block. The number of patients with post spinal hypotension and the number of boluses of ephedrine given were compared between groups with preoperative positive and negative baseline PLR tests.

Results: Fourty patients participated in the study. Eleven were fluid responsive (PLR +ve) with an average change in cardiac output following PLR of $18.06 .1 \pm 9.93 \%$ [range, $0.0-33.95 \%$ ]. Stroke volume increased in these patients by $10.6 \% \pm 10.20$ [range, $0.0-33.95 \%$ ]. In contrast, for the 29 patients who were fluid non responsive (PLR -ve), cardiac output and stroke volume changes following PLR averaged $-0.72 \pm 5.54 \%$ [range, $-14.29-8.71 \%$ ] and $1.64 \pm 7.57 \%$ [range, $-11.29-33.87 \%$ ], respectively $45 \%$ of the study patients developed post-spinal hypotension and received a vasopressor (ephedrine). PLR positive and negative patients were equally likely to experience spinal hypotension or receive vasopressors (ephredrine bolus) and
\end{abstract}

*Corresponding author: Mona Hossam EL Din Abdelhamid, Department of Anesthesia and Pain Management, Faculty of Medicine, Cairo University, Egypt, Tel: +20 1140434061; E-mail: monahossam29@yahoo.com

Citation: Abdullah MW, Abdelhamid MHED, Ali NAA, Moula AGA (2017) The Use of Passive Leg Raise Test to Predict Hypotension in Patients Undergoing Urological Procedures under Spinal Anesthesia. J Anesth Clin Care 4: 021.

Received: March 01, 2017; Accepted: June 13, 2017; Published: June 28 2017 these outcomes were not related to an individual's cardiac output response to the PLR test before spinal anesthesia.

Conclusion: The use of PLR test to predict the occurrence of hypotension in patients undergoing urological procedures under spinal anesthesia was not useful.

Keywords: Passive leg raise; Spinal anesthesia; Spinal hypotension; Urologic procedures

\section{Introduction}

Transurethral surgeries are common surgical procedures that can be performed under general or spinal anesthesia [1], spinal anesthesia has proved to be an excellent choice for such surgeries [2]. Hypotension after spinal anesthesia remains a common and potentially serious complication, despite the use of prophylactic ephedrine and fluid loading with crystalloids [3]. Hypotension during spinal anesthesia is due to sympathetic blockade which leads to vasodilatation with a reduction of systemic vascular resistance. Extensive block may lead to decreased venous return which is the main determinant of hypotension during central neuraxial blockade [4].

Most patients scheduled for endoscopic urological surgery are elderly and frequently suffered from cardiopulmonary, endocrine, or other co morbidities [5]. Increasing age is accompanied by decreased cardiac reserves, structural changes in the arterioles and changes in the autonomic nervous system. So, in theses elderly patients with limited cardiac reserve severe hypotension may be harmful [6].

Prevention of spinal hypotension in elderly patients includes prehydration with intravenous fluid to optimize cardiac preload. Preload can be assessed by measuring the cardiac output response to a transient Passive Leg Raise (PLR) test. The passive Leg raise test can predict fluid responsiveness and it is an alternative to predict the hemodynamic response to the fluid administration. It is based on that the lifting of the legs passively from the supine position into a $45^{\circ}$ position of both legs induces a gravitational transfer of blood from the lower limbs towards the thorax. This test is used recently to assess fluid responsiveness considering that the estimated venous pool moved from the legs is about 200-300 ml PLR recruits blood contained in the venous reservoir [7], reliably increasing cardiac output in preload dependent patients, but not in other patients [8]. The change in cardiac output following PLR is transient, and requires use of a cardiac output monitor with rapid response. The electrical cardiometry has the advantage of being portable, cost effective as a monitor for measurement of cardiac output in neonates, pediatrics and adults.

\section{Patients and Methods}

After the approval from Ethical committee of Kasr AL Ani Anesthesia Department, Faculty of Medicine, Cairo University, an informed written consent was taken from fourty patients, undergoing urological procedures under spinal anesthesia.

\section{Inclusion criteria}

- Patients aged 30-60 years olds undergoing urological surgeries

- Patients consented to spinal anesthesia will be enrolled

- ASA class I, II 


\section{Exclusion criteria}

- Patient refusal of spinal anesthesia

- Coagulation disorders

- Local infection at the site of spinal injection

- Patients with a known history of hypersensitivity to local anesthetics of the amide type

- $\quad \mathrm{BMI}>30 \mathrm{Kg} / \mathrm{m}^{2}$

- Anatomical deformities of the spine eg., kyphoscoliosis

All patients had an overnight fast of 8 hours and received routine intravenous prehydration consisting of lactated Ringer's solution 500 $\mathrm{ml} 30 \mathrm{~min}$ before the PLR test and spinal anesthesia.

Routine monitors was attached to the patients including ECG, pulse oximetry and non invasive blood pressure measurement Portable noninvasive hemodynamic monitor (electrical cardiometry) was placed for continuous monitoring of heart rate (Figure 1), cardiac output and stroke volume by placement of four electrodes, two dual-electrode skin sensors on the upper thorax or back, and two on the flanks or lateral sub coastal regions.

Before administration of spinal anesthesia, hemodynamic parameters were measured using electrical cardiometry for the PLR test with the patient lying flat.

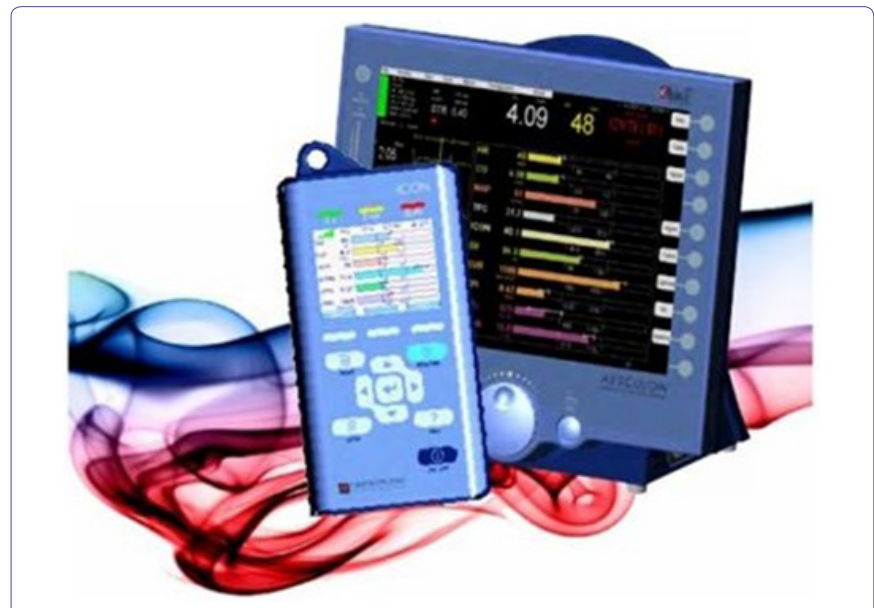

Figure 1: Portable Noninvasive Hemodynamic Monitor (electrical cardiometry) OSYPKA Medical Berlin- Germany.

Patients were still for 5 min to obtain stable hemodynamic measurements, following which a custom 45 degree wedge was placed under the legs to elevate them while continuously recording cardiac output by electrical cardiometry. After $5 \mathrm{~min}$, the wedge was removed and the legs were returned to the normal resting position. The hemodynamic response to PLR was quantified as the percent change in cardiac output from the baseline condition to the maximum cardiac output achieved during the second or third minute following the leg raise.

Patients were divided into two groups based on their hemodynamic response to the PLR test. They were considered fluid responsive (PLR positive) when cardiac output increased by more than $12 \%$. Patients not meeting this criterion were considered fluid nonresponsive (PLR negative). After completion of the PLR test, routine preparations for operation under spinal anesthesia were made, standard monitoring with electrocardiography, automated Non-Invasive Arterial Pressure (NIAP) measurement, and pulse oximetry was performed Electrical
Cardiometry was positioned so that the anesthesiologist was blinded to its measurements (including the PLR test).Clinical decision-making was based solely on routine blood pressure, ECG and pulse oximetry.

Spinal anesthesia was induced in the sitting position at the level of L 4-5 interspaces with a midline approach using a $22 \mathrm{G}$ Quincke needle under aseptic conditions. After confirmation of free flow and clear cerebrospinal fluid, Heavy Bupivacaine(0.5\%) $3 \mathrm{ml}$ with $25 \mu \mathrm{g}$ fentanyl was injected intrathecally over $15-20$ seconds and maintenance fluid $(1.5 \mathrm{ml} / \mathrm{kg} / \mathrm{hr}$ ) using crystalloid (Hartmann's solution) was infused continuously in all patients.

Patients were then turned to the supine position for 3-5 minutes and the height of the block was assessed. Meanwhile, heart rate, systemic arterial blood pressure, and oxygen saturation were monitored. When a T6 Sensory level was achieved, then patients were placed in the lithotomy position and surgery started.

Systemic arterial pressure was recorded at 3 minutes intervals at the onset of the block, 5 minutes intervals for the following $30 \mathrm{~min}$ utes, then 15 minutes intervals until the resolution of the block. Oxygen was administered to all patients via a nasal cannula and ephedrine was administered as a $5 \mathrm{mg}$ bolus if hypotension occurred, Post spinal hypotension was defined as mean arterial blood pressure decreased by $>20 \%$ of the patient's lowest baseline value (taken after the PRL test and before spinal anesthesia).

The number of patients with post-spinal hypotension and the number of boluses of ephedrine given were compared between groups with preoperative positive and negative baseline PLR tests.

\section{Data collection}

Demographic data (Age, Sex, ASA physical status)

Hemodynamic data (HR, MAP, $\mathrm{CO}, \mathrm{SaO}_{2}$ )

\section{Primary outcome}

To test effectiveness of PLR test as predictor for spinal hypotension in patients undergoing elective urological procedures.

\section{Secondary outcome parameters}

Evaluate effect of ephedrine in controlling hypotension in these patients.

\section{Statistical analysis}

Data were coded and entered using the statistical package SPSS version 22. Data was summarized using mean and standard deviation for quantitative variables and frequencies (number of cases) and relative frequencies (percentages) for categorical variables. Comparisons between groups were done using unpaired $t$ test for comparing categorical data, Chi square $(\chi 2)$ test was performed. Exact test was used instead when the expected frequency is less than 5 Correlations between quantitative variables were done using Spearman correlation coefficient $\mathrm{P}$ values less than 0.05 were considered as statistically significant.

\section{Results}

Total number of patients 40

PLR +ve $=11$

PLR $-\mathrm{ve}=29$ 


\section{Demographic data}

Age, ASA physical status and sex showed no statistical significant difference between the two studied groups. ( $\mathrm{P}$ value $>0.05$ ) (Tables 1,2)

\begin{tabular}{|c|c|c|c|c|c|c|}
\hline \multirow{2}{*}{} & & \multicolumn{2}{|c|}{ PLR +ve } & \multicolumn{2}{c|}{ PLR -ve } & P value \\
\cline { 3 - 7 } & & Count & Percent & Count & Percent & \\
\cline { 2 - 6 } Sex & Male & 9 & $81.8 \%$ & 24 & $82.8 \%$ & \multirow{2}{*}{1} \\
\cline { 2 - 6 } & Female & 2 & $18.2 \%$ & 5 & $17.2 \%$ & \\
\hline \multirow{2}{*}{ ASA } & $\mathrm{I}$ & 5 & $36.4 \%$ & 16 & $55.2 \%$ & \multirow{2}{*}{0.095} \\
\cline { 2 - 6 } & $\mathrm{II}$ & 6 & $45.5 \%$ & 13 & $44.8 \%$ & \\
\hline
\end{tabular}

\begin{tabular}{|c|c|c|c|c|c|}
\hline & \multicolumn{2}{|r|}{ PLR +ve } & \multicolumn{2}{|r|}{ PLR -ve } & \multirow[b]{2}{*}{$P$ value } \\
\hline & Mean & Standard Deviation & Mean & Standard Deviation & \\
\hline Age & 50.18 & 7.53 & 43.55 & 14.80 & 0.072 \\
\hline
\end{tabular}

Data expressed as mean $\pm(\mathrm{SD})$.

Fourty patients participated in the study. Eleven were fluid responsive (PLR + ve) with an average change in cardiac output following PLR of 18.06. \pm 6 [range $12.7-33.95 \%$ ]. Stroke volume increased in these patients by $16.03 \pm 4.02$ [range, $12-29.63 \%$ ]. In contrast, for the 29 patients who were fluid non responsive (PLR -ve), cardiac output and stroke volume changes following PLR averaged $0.72 \pm 5.54$ [range $-14.29-8.71 \%$ ] and $1.64 \pm 7.57 \%$ [range- $1.29-33.87 \%$ ], respectively as shown in tables $3 \& 4$.

\begin{tabular}{|c|c|c|c|c|}
\hline & \multicolumn{4}{|c|}{ PLR +ve } \\
\hline & Mean & Standard Deviation & Minimum & Maximum \\
\hline $\begin{array}{c}\text { Cardiac output } \\
\text { change }\end{array}$ & 18.06 & 6 & 12.7 & 33.95 \\
\hline $\begin{array}{c}\text { Stroke volume } \\
\text { change }\end{array}$ & 10.63 & 4.02 & 12 & 29.63 \\
\hline
\end{tabular}

Table 3: Change of cardiac output in PLR + ve patients.

\begin{tabular}{|c|c|c|c|c|}
\hline & \multicolumn{4}{|c|}{ PLR -ve } \\
\hline & Mean & Standard Deviation & Minimum & Maximum \\
\hline $\begin{array}{c}\text { Cardiac output } \\
\text { change }\end{array}$ & -0.72 & 5.54 & -14.29 & 8.71 \\
\hline $\begin{array}{c}\text { Stroke volume } \\
\text { change }\end{array}$ & 1.64 & 7.57 & 11.29 & 33.87 \\
\hline
\end{tabular}

Table 4: Change of cardiac output in PLR -ve patients

Data expressed as mean $\pm(\mathrm{SD})$.

There was statistical significant difference in change in cardiac output between the two groups (Figure 2).

There was no statistical significant difference in baseline hemodynamic data before passive leg raising test between the two groups (Table 5).

There was no statistical significant difference between the 2 groups regarding change in mean $\mathrm{ABP}$ and heart rate, 45\% (18/40) of the study patients experienced at least one episode of post spinal hypotension between the initiation of spinal anesthesia and the end of the study period (Figures 3,4).

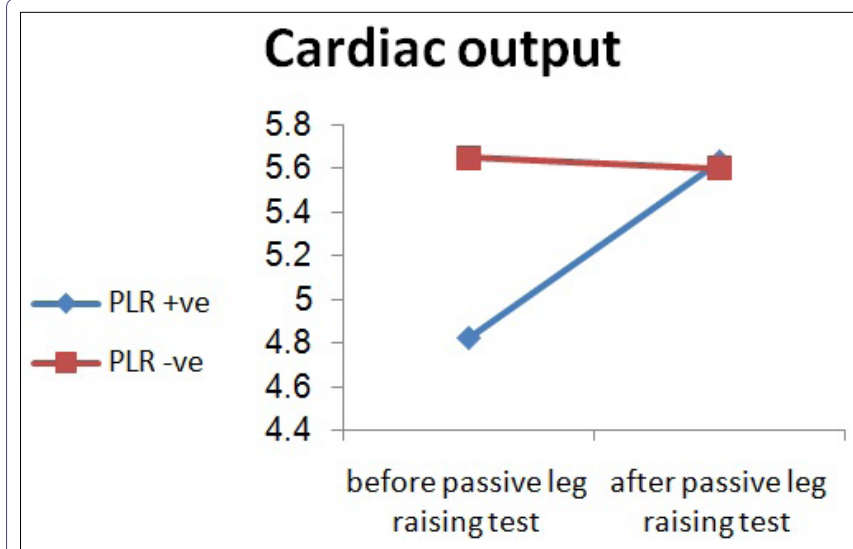

Figure 2: Comparison between the two groups regarding changes in cardiac output (L/min) before and after passive leg raising test.

\begin{tabular}{|c|c|c|c|c|c|}
\hline & \multicolumn{2}{|c|}{ PLR +ve } & \multicolumn{2}{c|}{ PLR -ve } & P value \\
\hline & Mean & $\begin{array}{c}\text { Standard } \\
\text { Deviation }\end{array}$ & Mean & $\begin{array}{c}\text { Standard } \\
\text { Deviation }\end{array}$ & \\
\hline $\begin{array}{c}\text { Cardiac output } \\
\text { (L/min) }\end{array}$ & 4.82 & 1.13 & 5.65 & 1.19 & 0.053 \\
\hline $\begin{array}{c}\text { Stroke volume } \\
\text { (mL/beat) }\end{array}$ & 65.00 & 11.45 & 71.48 & 11.63 & 0.122 \\
\hline $\begin{array}{c}\text { Heart rate } \\
\text { (beat/min) }\end{array}$ & 71.82 & 8.62 & 78.90 & 12.23 & 0.087 \\
\hline $\begin{array}{c}\text { Mean ABP } \\
\text { (mmHg) }\end{array}$ & 85.45 & 5.63 & 85.90 & 10.74 & 0.898 \\
\hline $\begin{array}{c}\text { so } \\
\text { (mm }\end{array}$ & 97.91 & 1.30 & 98.69 & 1.28 & 0.095 \\
\hline
\end{tabular}

Table 5: Base line hemodynamic data in all patients before PLR test.

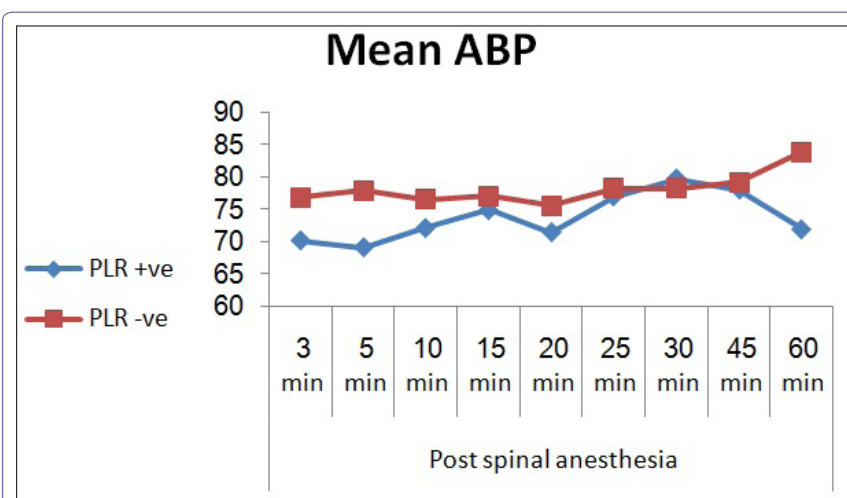

Figure 3: Changes in mean ABP after spinal anesthesia in both groups.

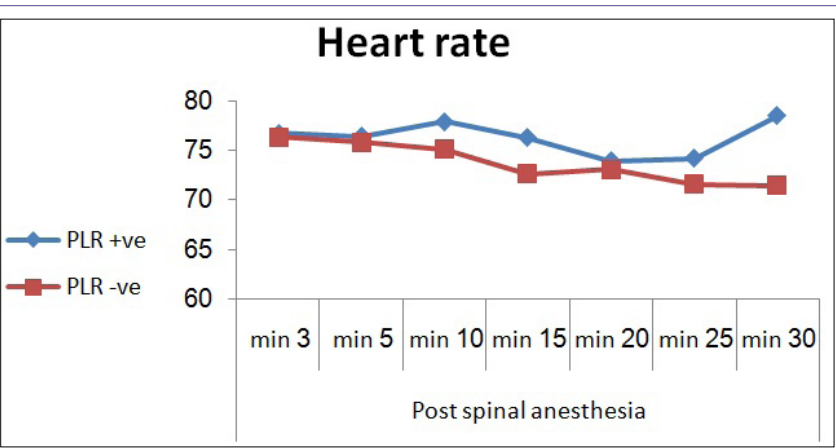

Figure 4: Change in heart rate after spinal anesthesia in both groups. 
Although there was no statistical significant difference between the two age groups regarding change in mean ABP, $p$ value (0.282) but most patients above 50 years $12 / 17(70.5 \%)$ developed hypotension and needed ephedrine with only about (43.4\%) $10 / 23$ of patients $<50$ years needed ephedrine boluses as shown in table 6 .

\begin{tabular}{|c|c|c|c|c|c|c|}
\hline \multicolumn{2}{|c|}{} & \multicolumn{2}{|c|}{ Age>50years } & \multicolumn{2}{c|}{ Age<50years } & \multirow{2}{*}{ P value } \\
\cline { 2 - 6 } & Count & Percent & Count & Percent & \\
\hline \multirow{2}{*}{$\begin{array}{c}\text { Ephedrine } \\
\text { boluses }\end{array}$} & yes & 12 & $70.5 \%$ & 10 & $43.4 \%$ & \multirow{2}{*}{0.282} \\
\cline { 2 - 6 } & no & 5 & $29.4 \%$ & 13 & $56.5 \%$ & \\
\hline
\end{tabular}

Table 6: Comparison between two different age groups in occurrence of hypotension and need for ephedrine boluses.

Vasopressor administration also did not differ significantly between fluid responsive (PLR +ve) and fluid nonresponsive (PLR-ve) patients. Approximately 55\% (22/40) of patients in both groups received at least one dose of vasopressor (8/11) $72.7 \%$ of fluid responsive patients and (14/29) 48.3\% fluid non-responsive patients, $\mathrm{P}=0.286$ ), with a median of 1-2 doses per patient in both groups (Tables 7,8 ).

\begin{tabular}{|c|c|c|c|c|c|c|}
\hline \multicolumn{2}{|c|}{} & \multicolumn{2}{|c|}{ PLR +ve } & \multicolumn{2}{c|}{ PLR -ve } & \multirow{2}{*}{ P value } \\
\cline { 3 - 6 } \multicolumn{2}{|c|}{} & Count & Percent & Count & Percent & \\
\hline \multirow{2}{*}{$\begin{array}{c}\text { Ephedrine } \\
\text { boluses }\end{array}$} & Yes & 8 & $72.7 \%$ & 14 & $48.3 \%$ & \multirow{2}{*}{0.286} \\
\cline { 2 - 6 } & No & 3 & $27.3 \%$ & 15 & $51.7 \%$ & \\
\hline
\end{tabular}

Table 7: Total number of ephedrine bolus given in PLR +ve and PLR -ve groups.

\begin{tabular}{|c|c|c|c|c|c|c|}
\hline & & PLR +ve & & & PLR -ve & \multirow{2}{*}{ P value } \\
\hline & & Count & Percent & Count & Percent & \\
\hline & 0 & 3 & $27.3 \%$ & 15 & $51.7 \%$ & \\
\cline { 2 - 6 } & 1 & 1 & $9.1 \%$ & 1 & $3.4 \%$ & \multirow{2}{*}{0.101} \\
\cline { 2 - 6 } $\begin{array}{c}\text { Ephedrine boluses } \\
\text { number }\end{array}$ & 2 & 1 & $9.1 \%$ & 8 & $27.6 \%$ & \\
\cline { 2 - 6 } & 3 & 5 & $45.5 \%$ & 4 & $13.8 \%$ & \\
\cline { 2 - 6 } & 4 & 1 & $9.1 \%$ & 1 & $3.4 \%$ & \\
\hline
\end{tabular}

Table 8: Comparison between number of ephedrine bolus in both groups.

\section{Discussion}

In this study fourty patients ( 33 males and 7 females) were enrolled eleven of them exhibited significant fluid responsiveness (PLR +ve) as indexed by a $>12 \%$ increase in cardiac output following PLR test using Portable Noninvasive Hemodynamic Monitor (electrical cardiometry) despite having received routine prehydration with a $500 \mathrm{ml}$ crystalloid fluid bolus while 29/40 patients were fluid non responsive (PLR -ve). Furthermore, $45 \%$ of the study patients developed post spinal hypotension and 55\% received a vasopressor (ephedrine).

PLR positive and negative patients were equally likely to experience spinal hypotension or receive vasopressors (ephedrine bolus) and these outcomes were not related to an individual's cardiac output response to the PLR test before spinal anesthesia.

The main findings of this study indicate that the cardiac output response to the PLR test using portable noninvasive hemodynamic monitor (electrical cardiometry ) is not predictive of either hypotension or vasopressor use in patients undergoing urological procedures after spinal anesthesia.

The identification of patients with a high risk to develop hypotension during spinal anesthesia has already been an object of a study resulting in a logistic model which considered sensory level above T6 and more than 50 years of age as independent predictors of hypotension during spinal anesthesia [9].

The study done by Getúlio Rodrigues de Oliveira Filho aimed at evaluating several preanesthetic factors as independent hypotension predictors during the first 20 minutes after spinal hyperbaric bupivacaine as age equal to or above 45 years [10], female gender and upper sensory block above T6. The results of that study concluded that age has been related to hypotension and, female patients had more chances of developing hypotension than males also upper sensory block above T6 had more chances of developing hypotension.

In this study PLR test was used as a predictor for post spinal hypotension. PLR represents a simple method of transiently increasing systemic venous return by transferring blood from the legs to the intrathoracic compartment $[11,12]$. PLR can be considered as a "self fluid challenge" since this phenomenon reverses once legs are returned to the supine position and does not persist if the legs are held elevated for extended intervals. Thus, PLR allows for a rapid and reversible preload challenge without needing to infuse fluid.

Many studies have analyzed postural hemodynamic changes to confirm suspected hypovolaemia, but the accuracy of previously described clinical signs to diagnose hypovolaemia not due to blood loss is very low lack of information concerning this population was emphasized in a review published in 1999 [13]. Leg rising was very recently used in selected critically ill patients [14].

Monnet et al., using esophageal doppler, found that an increase in aortic blood flow by more than $12 \%$ was predictive of a greater than $15 \%$ increase in CO after fluid expansion [15].

Similarly Lafanechere et al., reported that an increase in aortic flow greater than $8 \%$ during PLR predicted an increase in aortic blood flow after volume infusion [16]. Both studies were performed in intubated and mechanically ventilated patients and used esophageal doppler to measure $\mathrm{CO}$, These findings observed in mechanically ventilated patients cannot be extrapolated to non sedated and non intubated patients. While in this study PLR test was done in none sedated and spontaneously breathing patients under spinal anesthesia only.

Spinal anesthesia is popular for endoscopic urological surgery because of early recognition of symptoms caused by over hydration, Transurethral Resection of Prostate (TURP) syndrome and bladder perforation. Patients, who are candidates for endoscopic urological surgery, are frequently elderly and have a preexisting cardiovascular and respiratory diseases [17].

In this study although there was no significant statistical difference regarding age groups concerning change in mean $\mathrm{ABP}$ and occurrence of hypotension ( $\mathrm{P}$ value 0.282 ) but most patients above 60 years old 12/17 patients (70.5\%) developed hypotension and needed ephedrine with only about (43.4\%) 10/23 of patients $<50$ years old needed ephedrine boluses this could be explained that with advancing age the central and peripheral nervous system degenerate. These changes may have an impact on neural block characteristics and the pharmacology of local anesthetic agents. A reduction in the number of neurons within the spinal cord, deterioration of myelin sheaths and connective tissue barriers, changes in the anatomical configuration of the lumbar and thoracic spine, possible reduction in the volume of cerebrospinal fluid and slowing of the conduction velocity in peripheral nerves, especially the motor nerves, all contribute to altered nerve block 
characteristics following epidural and subarachnoid administration of local anesthetic agents [18].

A combination of fluids and vasopressors when given in the first 5-10 min (when the block is evolving) seems to be the most effective treatment for hypotension after spinal or epidural anaesthesia in elderly patients [19].

One of the most effective methods of preventing hypotension is to avoid a high sensory block. Continuous spinal anaesthesia allows the administration of small incremental doses of local anaesthetics and thus provides a more controllable sensory and sympathetic level. It is a very effective technique in providing hemodynamic stability in elderly patients undergoing lower extremity surgery [20].

Meirowitz $\mathrm{N}$ et al., studied the use of passive leg raising test in predicting post spinal hypotension during cesarean delivery with a Non Invasive, Continuous Cardiac Output Monitor (NICOM $\left.{ }^{\star}\right)$ [21]. In that study 40 pregnant women undergoing cesarean section under spinal anesthesia were divided into two groups based on their performance on the passive leg raise test those whom had increased cardiac output $>12 \%$ following passive leg raise test were considered fluid responsive (PLR +ve). The incidence of hypotension, defined as mean arterial blood pressure decreased by $>20 \%$ of the patient's lowest baseline value was compared between the two groups. Vasopressor use was also compared between the groups, Results : 9/40 patients were fluid responsive (PLR +ve) and 31/40 patients were fluid non responsive (PLR-ve). The groups had similar demographics and baseline hemodynamic parameters. No significant differences were seen between the groups in the incidence of spinal hypotension and vasopressor use. Non Invasive Cardiac Output Monitoring (NICOM monitor) was used to measure change in cardiac output.

Kinsella et al., Norris used to predict hypotension at cesarean delivery after spinal anesthesia using the "tilt test", in which 27 recruited patients from the supine position were sitting up straight with the legs hanging down unsupported over the side of the bed. If there was an increase in heart rate or a decrease in systolic pressure, the patients would have develop hypotension after the spinal puncture. The authors concluded that this test was not useful to predict hypotension after spinal anesthesia [22].

In a study done by R Bashir et al., concluded that there appears to be no role of preemptive hydration before spinal anaesthesia especially for non obstetric elective surgeries in elderly and in case hypotension occurs [23], it should be treated by boluses of vasopressors.

In a study done by Hemmingsen C, Poulsen JA and Risbo showed comparison of two different measures intended to reduce hypotension post spinal anesthesia in elderly patients showed greater hemodynamic stability with preemptive injection ephedrine [24], $30 \mathrm{mg}$ (i.m.), given 10 min before subarachnoid block compared with an infusion of injection polygeline $3.5 \% 500 \mathrm{ml}$.

In this study all patient received $500 \mathrm{ml}$ of crystalloid (lactated ringes) as a preload to control post spinal hypotension, about $45 \%$ of them developed hypotension.

Several studies investigated benefit of preload or coload to decrease incidence of post spinal hypotension, Rufeng Xie study suggested that use of moderate volume of colloid preload is more effective than crystalloids in maintaining the $\mathrm{CO}$ and hemodynamic stability in elderly patients [25].

Gunuseni study concluded that a combination of an ephedrine infusion at $1.25 \mathrm{mg}$ minute with a crystalloid co load was more effective than fluid preloading with crystalloid or colloid in the prevention of moderate and severe hypotension [26].

\section{Limitations}

The study has several limitations as the results were obtained in a small number of patients. So, a larger sample size would be needed to show a relationship between fluid responsiveness and post spinal hypotension. A further limitation is lack of standardization of vasopressor use, also we suggest to concentrate on patients with age above fifty years to specify more about relationship between old age and the higher incidence of post spinal hypotension.

\section{Conclusion}

In the current study, results showed that the use of passive leg raising test to predict occurrence of hypotension in patients undergoing urological procedures under spinal anesthesia was not useful.

\section{References}

1. Lepage JY, Rivault O, Karam G, et al. (2005) Anesthesia and Prostate surgery. Ann Fr Anesth Reanim 24: 397-411.

2. Kararmaz A, Kaya S, Turhanoglu S, Ozyilmaz MA (2003) Low-dose bupivacaine-fentanyl spinal anaesthesia for transurethral prostatectomy. Anesthesia 58: 526-530.

3. Hartmann B, Junger A, Klasen J, Benson M, Jost A, et al. (2002) The incidence and risk factors for hypotension after spinal anesthesia induction: an analysis with automated data collection. Anesth Analg 94:1521-1529.

4. Carpenter RL, Caplan RA, Brown DL, Stephenson C, Wu R (1992) incidence and risk factors for side effects of spinal anesthesia. Anesthesiology 76: 906916.

5. Critchley LA (1996) Hypotension, subarachnoid block and the elderly patient. Anesthesia 51: 1139-1143.

6. Simon MJ, Veering BT, Stienstra R, Van Kleef JW, Burm AG (2002) The effects of age on neural blockade and hemodynamic changes after epidural anesthesia with ropivacaine. Anesth Analg 94: 1325-1330.

7. Pinsky MR, Payen D (2005) functional hemodynamic monitoring. Crit Care 9: 566-572.

8. Monnet X, Teboul JL (2008) Passive leg raising. Intensive Care Med 34: 659663.

9. Tarkkila P, Isola J (1992) A regression model for identifying patients at high risk of hypotension, bradycardia and nausea during spinal anesthesia. Acta Anaesthesiol Scand 36: 554-558.

10. Filho GRDO, Garcia JHS, Goldschimidt R, Mago AJD, Cordeiro MA, et al. (2001) Predictors of Early Hypotension During Spinal Anesthesia. Rev Bras Anestesiol 51.

11. Rutlen DL, Wackers FJ, Zaret BL (1981) Radionuclide assessment of peripheral intravascular capacity: A technique to measure intravascular volume changes in the capacitance circulation in man. Circulation 64: 146-152.

12. Reich DL, Konstadt SN, Raissi S, Hubbard M, Thys DM (1989) Trendelenburg position and passive leg raising do not significantly improve cardiopulmonary performance in the anesthetized patient with coronary artery disease. Crit Care Med 17: 313-317.

13. McGee S, Abernethy WB 3rd, Simel DL (1999) The rational clinical examination. Is this patient hypovolemic? JAMA 281:1022-1029.

14. Boulain T, Achard JM, Teboul JL, Richard C, Perrotin D, et al. (2002) Changes in BP induced by passive leg raising predict response to fluid loading in critically ill patients. Chest 121: 1245-1252.

15. Monnet X, Rienzo M, Osman D, Anguel N, Richard C, et al. (2006) Passive leg raising predicts fluid responsiveness in the critically ill. Crit Care Med 34: 1402-1407. 
16. Lafanechere A, Pene F, Goulenok C, Delahaye A, Mallet V, et al. (2006) Changes in aortic blood flow induced by passive leg raising predict fluid responsiveness in critically ill patients. Crit Care 10: 132.

17. Mebust WK, Holtgrewe HL, Cockett ATK, Peters PC, Writing committee (2002) Transurethral prostatectomy: immediate and postoperative complications. A cooperative study of 13 participating institutions evaluating 3,885 patients. J Urol 167: 999-1003.

18. Tsui BC, Wagner A, Finucane B (2004) Regional anaesthesia in the elderly: a clinical guide. Drugs Aging 21: 895-910.

19. Buggy D, Higgins P, Moran C, O' Brien D, O'Donovan F, et al. (1997) Prevention of spinal anesthesia-induced hypotension in the elderly: comparison between preanesthetic administration of crystalloids, colloids, and no prehydration. Anesth Analg 84: 106-110.

20. Minville V, Fourcade O, Grousset D, Chassery C, Nguyen L, et al. (2006) Spinal anesthesia using single injection small-dose bupivacaine versus continuous catheter injection techniques for surgical repair of hip fracture in elderly patients. Anesth Analg 102: 1559-1563.

21. Meirowitz N, Katz A, Danzer B, Siegenfeld R (2012) Can the passive leg raise test predict spinal hypotension during cesarean delivery? An observational pilot study. Int J Obstet Anesth 21: 324-328.
22. Kinsella SM, Norris MC (1996) Advance prediction of hypotension at cesarean delivery under spinal anesthesia. Int J Obstet Anesth 5: 3-7.

23. Bashir R, Curcoo S, Shora A, Qazi M, Farooqi A, et al. (2007) Hemodynamic changes following spinal anaesthesia in patients undergoing transurethral resection of prostrate (TURP): A comparison between preloading with crystalloids and no preloading. The Internet Journal of Anesthesiology 18: 1.

24. Hemmingsen C, Poulsen JA, Risbo A (1989) Prophylactic ephedrine during spinal anaesthesia: double-blind study in patients in ASA groups I-III. Br J Anaesth 63: 340-342.

25. Xie R, Wang L, Baoa H (2011) Crystalloid and colloid preload for maintaining cardiac output in elderly patients undergoing total hip replacement under spinal anesthesia. J Biomed Res 25: 185-190.

26. Gunusen I, Karaman S, Ertugrul V, Firat V (2010) Effects of fluid preload (crystalloid or colloid) compared with crystalloid co-load plus ephedrine infusion on hypotension and neonatal outcome during spinal anaesthesia for caesarean delivery. Anaesth Intensive Care 38: 647-653. 